\title{
High consistency mechano-enzymatic pretreatment for kraft fibres: effect of treatment consistency on fibre properties
}

\author{
Jenni Rahikainen (D) Outi Mattila • Thaddeus Maloney (D) Ville Lovikka • \\ Kristiina Kruus (iD) Anna Suurnäkki • Stina Grönqvist $($ D
}

Received: 5 December 2019/ Accepted: 22 March 2020/Published online: 31 March 2020

(C) The Author(s) 2020

\begin{abstract}
Fibre reactivity is essential for cellulose dissolution and derivatisation and a porous fibre structure is one key determinant for a highly reactive pulp. Mechanical and enzymatic treatments are known to improve fibre reactivity and more recently, the combination of mechano-enzymatic treatment has been shown to synergistically enhance the beneficial effect. The aim of this work was to do a systematic study on the effect of dry matter content during enzymatic modification of fibres and define the conditions that optimally improve fibre porosity. The
\end{abstract}

J. Rahikainen $(\bowtie) \cdot$ O. Mattila $\cdot$ K. Kruus ·

A. Suurnäkki · S. Grönqvist

VTT Technical Research Centre of Finland, Espoo,

Finland

e-mail: jenni.rahikainen@vtt.fi

T. Maloney · V. Lovikka

Department of Bioproducts and Biosystems, Aalto

University, Espoo, Finland

Present Address:

V. Lovikka

Department of Chemistry, University of Helsinki, Espoo,

Finland

Present Address:

K. Kruus

School of Chemical Engineering, Aalto University,

Espoo, Finland

Present Address:

A. Suurnäkki

Metsä Fibre Oy, Espoo, Finland combined mechano-enzymatic treatments at 15-25 w\% consistency had the most pronounced effect on fibre porosity and morphology analysed by solute exclusion technique, nitrogen sorption and scanning electron microscopy. Light microscopy imaging confirmed that the combined mechano-enzymatic treatment at high consistency ( $>10 \mathrm{w} \%)$ resulted in extensive fibrillation of the treated fibres which was not observed after sole mechanical or enzymatic treatments.

Keywords Enzyme $\cdot$ Endoglucanase $\cdot$ High consistency $\cdot$ Fibre modification · Fibre reactivity · Porosity

\section{Introduction}

Environmental concerns have raised interest in products made of renewable raw materials in a sustainable manner. Cellulose, the most abundant biopolymer on the Earth has versatile properties for various material applications. Utilisation of cellulosics, especially in the areas of textiles and cellulose derivatives, has been an active area of research. Compared to the volumes in paper and board manufacture, the use of cellulose in high-value products is nevertheless still low. Improved accessibility and reactivity of cellulosic fibres for dissolution and chemical modifications 
would enable the use of cellulose in a wider scale. Currently, harsh chemistry is used for cellulose dissolution and modification and environmentally benign fibre pretreatments that improve the accessibility and reactivity of cellulose would enable the development of processes with more sustainable solvent systems.

Cellulose-rich fibres are derived from wood via pulping and depending on the end-use, the pulps are usually bleached. Pulping and bleaching remove mostly lignin, which detaches the fibres and creates pores in the fibre walls (Stone and Scallan 1965). For pulp reactivity, the fibre pore structure is one important factor since it governs the accessibility of reactants and solvents to the inner regions of the cell wall. The fibre wall pores exist in the water-swollen state and collapse to a non-porous solid upon drying. Upon rewetting, the pores are partially regenerated (Stone and Scallan 1968; Lovikka et al. 2016). The conformability and swelling capacity of cellulosic fibres, which is lost upon drying, cannot be completely recovered by rewetting the fibres. In addition to drying history, changes in chemical environment and mechanical processing affect the pore structure of the cell wall (Pönni et al. 2013; Lovikka et al. 2016, 2018).

Enzymes originating from wood degrading microorganisms are natural tools for fibre modification. As specific catalysts they can be used for targeted modification of the different polymers in pulps. Cellulose acting hydrolytic enzymes, such as endoglucanases, have been identified as potential tools for increasing fibre reactivity (Rahkamo et al. 1996; Köpcke et al. 2008; Gehmayr et al. 2011). Endoglucanases are well known for their ability to lower the degree of polymerization of cellulose in pulp (Rahkamo et al. 1996) but they are also shown to increase fibre porosity ( $\mathrm{Li}$ et al. 2018) and the microfibril distance in fibres (Virtanen et al. 2015) which indicates that the enzymes may also be capable of loosening the coherence of microfibril bundles in fibre walls.

Mechanical forces can also be used to disrupt the cell wall structure, allowing the cell walls to expand and thus increase the surface area that is accessible to enzymes (Grönqvist et al. 2014). Considerable amount of work has been carried out to study the effect of mechanical and enzymatic treatments and their combinations at low consistency (Seo et al. 2000; Miao et al. 2015; Wang et al. 2020). However, recent studies show that combined mechanical and enzymatic treatments at high consistency act synergistically resulting in a more pronounced effect than if the mechanical and enzymatic treatments follow each other (Grönqvist et al. 2015; Wang et al. 2015). At high consistency the low water content causes fibre-fibre friction which disrupts the fibre structure and enhances enzyme accessibility to the fibre walls (Rahikainen et al. 2019). High dry matter content has also a positive effect on how enzymes find, recognise and adsorb onto cellulose surfaces (Várnai et al. 2013; Wang et al. 2015). From an industrial point-of-view, high consistency treatments can help to reduce operational costs as well as water and energy footprint. Thus far, mechanoenzymatic pretreatment at high consistency has been shown to improve kraft pulp reactivity for the production of cellulose esters (Willberg-Keyriläinen et al. 2019) and for improving alkaline solubility of dissolving grade pulp (Grönqvist et al. 2015).

Here, the aim was to study the effect of dry matter content (10-30\% w/w) during enzymatic modification of fibres and define the conditions that optimally improve cellulose accessibility and fibre porosity. Mechano-enzymatic treatments at high consistency were compared to sole mechanical and enzymatic treatments or sequential mechanical and enzymatic treatments. The treated fibres were analysed with respect to fibre swelling (WRV), fibre porosity in wet state (solute exclusion) and after critical point drying (nitrogen sorption). Visual appearance was evaluated using light microscopy and scanning electron microscopy and changes in molecular weight were assessed by following pulp viscosity and molecular weight distribution.

\section{Materials and methods}

Pulp and enzyme

Bleached and dried softwood kraft pulp from Imatra Kaukopää mill (Stora Enso, Finland) was used. The chemical composition of the pulp was determined after a two-step sulphuric acid hydrolysis following the protocol published by NREL (Sluiter et al. 2008). The major pulp components were cellulose (80.3\%), xylan (10.4\%), glucomannan (8.4\%) and klason lignin (0.9\%). 
Prior to use, the pulp was cold disintegrated according SCAN-C 18:65, except that the amount of pulp was $50 \mathrm{~g}$ (o.d.) and the pulp was mixed with $2.7 \mathrm{~L}$ of deionized water. After disintegration, the pulp was vacuum-filtered $(60 \mu \mathrm{m})$ and homogenized with a Kenwood kitchen mixer.

A commercial endoglucanase-rich enzyme preparation (Fibercare R) from Novozymes (Bagsværd, Denmark) was used. The major cellulolytic activity of the enzyme preparation was endoglucanase activity: $2760 \mathrm{nkat} / \mathrm{ml}$ assayed at $\mathrm{pH} 5$ using hydroxyethylcellulose (HEC) as substrate (Ghose 1987). Negligible xylanase activity (4 nkat/ml) was assayed from the preparation at pH 5 (Bailey et al. 1992). For pulp treatments, the enzyme was dosed based on protein concentration (mg protein per gram of dry matter). Protein concentration of the commercial product was determined after protein precipitation and re-dissolution using a commercial kit (DC protein assay, BioRad Laboratories) which is based on the Lowrymethod (Lowry et al. 1951).

\section{Mechanical and enzymatic treatments}

Combined mechanical and enzymatic treatments $(10-30 \% \mathrm{w} / \mathrm{w})$ were carried out in a farinograph mixer (Brabender, Germany) equipped with z-shaped mixing blades (Fig. 1). Farinographs have been developed for measuring dough properties for the baking industry; however, the mixing unit is also applicable for laboratory-scale high-consistency treatments of pulp. The pulp was pre-heated to ca. $50{ }^{\circ} \mathrm{C}$ after which the enzyme $(0.25 \mathrm{mg}$ protein/g pulp) was added using a spray bottle to ensure even distribution. The treatments were carried out at $50{ }^{\circ} \mathrm{C}$ for $2 \mathrm{~h}$ using $30 \mathrm{rpm}$ mixing in ca. $20 \mathrm{mM}$ sodium acetate buffer (pH 5). The amount of wet pulp in the different treatments was kept constant (200-250 g). After the mechano-enzymatic treatment, the pulp was diluted with boiling water to inactivate the enzyme followed by sample boiling and washing with deionized water.

In the sequential mechanical and enzymatic treatments, the pulp was first treated mechanically in the farinograph mixer for $2 \mathrm{~h}$ as described earlier (without enzyme addition) and thereafter enzymatically at 5\% consistency (w/w) in a Linitest Plus (Atlas) test device which employs free fall mixing $\left(45 \mathrm{rpm}, 2 \mathrm{~h}, 50{ }^{\circ} \mathrm{C}\right.$, $\mathrm{pH}$ 5). The enzymatic reaction was stopped as described earlier.
All pulp treatments were done in duplicate except for some control treatments that are marked in the result table (Table 1). The experimental setting and nomenclature of the samples is presented in Fig. 2.

Analyses

Dissolved carbohydrates were analysed after secondary enzymatic hydrolysis of oligomeric products (Buchert et al. 1993) using the dinitrosalicylic acid (DNS) assay of reducing sugars (Sumner and Noback 1924; Bernfeld 1955).

The viscosity of the pulps (limiting viscosity number) was determined according to ISO 5351-1 using PSL Rheotek equipment (Poulten, Selfe \& Lee Ltd, UK). Molecular weight distributions of the pulp samples were determined after sample dissolution in DMAc/8\% $\mathrm{LiCl}$ according to the solvent exchange method with ethyl isocyanate derivatisation (Berthold et al. 2001). After complete dissolution, the samples were diluted with DMAc providing final $\mathrm{LiCl}$ concentration of $0.8 \%$. The samples were filtered $(0.45 \mu \mathrm{m})$ prior to size exclusion chromatography (SEC). The SEC measurements were performed using $2 \times$ PL gel MiniMixed A columns with a precolumn in DMAc/ $0.8 \% \mathrm{LiCl}$ eluent $\left(0.36 \mathrm{ml} / \mathrm{min}, \mathrm{T}=80{ }^{\circ} \mathrm{C}\right)$. The elution curves were detected using a Waters 2414 Refractive index detector. The molar mass distributions (MMD) were calculated against $8 \times$ pullulan $(6$ 100-708 $000 \mathrm{~g} / \mathrm{mol}$ ) standards, using Waters Empower 3 software. The Water retention value (WRV) was analysed according to SCAN C62:00.

The solute exclusion method (Stone and Scallan 1967,1968 ) was used to measure pulp swelling at two different length scales (Manninen et al. 2013; Grönqvist et al. 2014). A dextran probe (2 $000 \mathrm{kDa}$ ), with a Stokes diameter of $54 \mathrm{~nm}$, was used to measure the total water in the cell wall (fibre saturation point, FSP). Any pores larger than $54 \mathrm{~nm}$ are outside the range of the measurement. A $5 \mathrm{kDa}$ dextran with Stokes diameter of $3.2 \mathrm{~nm}$ was used to measure water in "micropores". Note that the definition of micropores in this paper deviates slightly from the official IUPAC definition of "pores less than $2 \mathrm{~nm}$ ". The micropore water includes water inside fibril aggregates, water held in the hemicellulose gel and water held in any interfibril pores less than $3.2 \mathrm{~nm}$. The mesoporosity is the difference between the FSP and the micropore water. The mesopore volume includes 


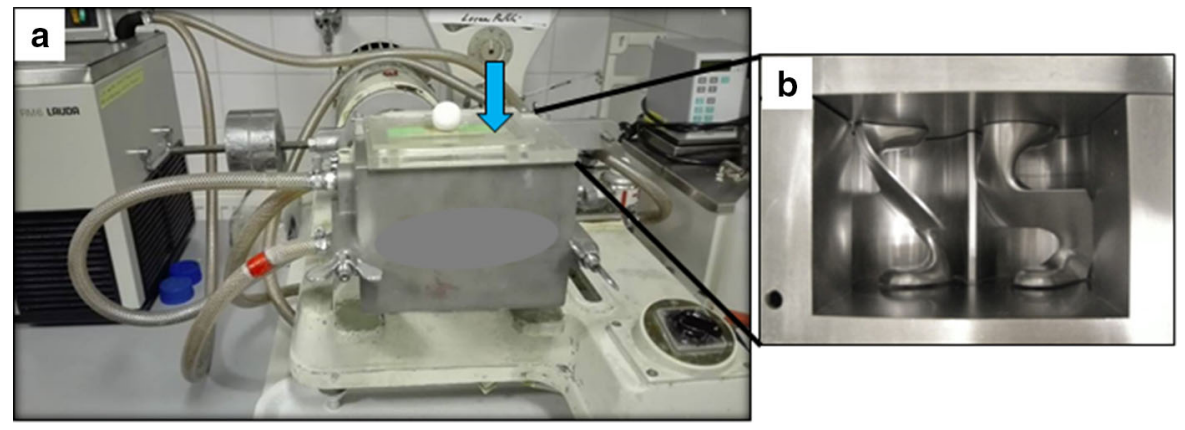

Fig. 1 Farinograph mixer used for high consistency pulp treatments. The ca. $0.5 \mathrm{~L}$ mixing unit is indicated with a blue arrow on panel a. Temperature of the mixing unit can be adjusted with water circulation (left from the mixing unit). A top down view of the mixing shows the two z-shaped mixing blades (panel b)

Table 1 Characterization of softwood kraft pulp (P) treated enzymatically (E), mechanically (M), in sequential mechanical and enzymatic treatments $(\mathrm{M}-\mathrm{E})$ or in combined mechano-enzymatic treatments $(\mathrm{ME})$

\begin{tabular}{|c|c|c|c|c|c|c|c|}
\hline Treatment & $\begin{array}{l}\text { Short } \\
\text { name }^{\mathrm{a}}\end{array}$ & $\begin{array}{l}\text { Mw } \\
(\mathrm{kDa})\end{array}$ & $\begin{array}{l}\text { Viscosity } \\
(\mathrm{ml} / \mathrm{g})\end{array}$ & $\begin{array}{l}\text { WRV } \\
(\mathrm{g} / \mathrm{g})\end{array}$ & $\begin{array}{l}\text { Micropores } \\
(\mathrm{ml} / \mathrm{g})\end{array}$ & $\begin{array}{l}\text { Mesopores } \\
(\mathrm{ml} / \mathrm{g})\end{array}$ & $\begin{array}{l}\text { Yield } \\
\text { loss } \\
(\mathrm{w} \%)\end{array}$ \\
\hline Untreated pulp & $\mathrm{P}$ & 700 & 810 & 1.14 & 0.52 & 0.35 & n.d \\
\hline Reference treatment at $5 \%$ without enzyme & $\mathrm{R} 5 \%$ & 660 & 800 & 1.20 & 0.54 & 0.37 & 0.1 \\
\hline Enzymatic treatment at $5 \%$ & $\mathrm{E} 5 \%$ & 340 & 450 & 1.46 & 0.61 & 0.50 & 1.3 \\
\hline \multirow{3}{*}{$\begin{array}{l}\text { Mechanical treatments }(\mathrm{M}) \text { at different } \\
\text { consistencies } 10-30 \%\end{array}$} & M10\% & 620 & 790 & 1.30 & 0.55 & 0.48 & 0.0 \\
\hline & M20\% & 590 & 780 & 1.29 & 0.58 & 0.43 & 0.0 \\
\hline & M30\%* & 490 & 750 & 1.27 & 0.57 & 0.46 & 0.0 \\
\hline \multirow[t]{3}{*}{$\begin{array}{l}\text { Sequential mechanical }(\mathrm{M}) \text { and enzymatic } \\
\text { (E) treatments }\end{array}$} & $\begin{array}{l}\mathrm{M} 10 \%- \\
\mathrm{E} 5 \% *\end{array}$ & 250 & n.d & 1.56 & 0.69 & 0.65 & 1.8 \\
\hline & $\begin{array}{l}\text { M20\%- } \\
\text { E5\%* }\end{array}$ & 290 & n.d & 1.56 & 0.63 & 0.66 & 1.5 \\
\hline & $\begin{array}{l}\text { M30\%- } \\
\text { E5\%* }\end{array}$ & 210 & n.d & 1.53 & 0.72 & 0.6 & 1.8 \\
\hline \multirow{5}{*}{$\begin{array}{l}\text { Combined mechano-enzymatic (ME) treatments } \\
\text { at different consistencies }(10-30 \%)\end{array}$} & ME10\% & 250 & 410 & 1.58 & 0.68 & 0.56 & 1.5 \\
\hline & ME15\% & 270 & 340 & 3.54 & 0.77 & 0.80 & 2.0 \\
\hline & ME20\% & 210 & 370 & 3.59 & 0.79 & 0.75 & 2.2 \\
\hline & ME25\% & 200 & 350 & 2.71 & 0.75 & 0.72 & 2.4 \\
\hline & ME30\% & 240 & 300 & 2.22 & 0.76 & 0.70 & 2.3 \\
\hline
\end{tabular}

Dry matter content in the treatment is indicated as weight percentage (\%). Weight average molecular weight (Mw), yield loss of pulp carbohydrates (w\%), viscosity, water retention value (WRV) and porosity (micro- and mesopores) measured by solute exclusion are shown. The pulp treatments were carried out in duplicates except for samples marked with *. n.d. = not determined. The data with standard deviations (except the yield loss) is also visualised in Figs. 3 and 4

${ }^{\mathrm{a}}$ The dry matter content in the mechanical (M) enzymatic (E) or combined (ME) treatment is indicated as a weight percentage

${ }^{\mathrm{b}}$ The amount of dissolved sugars was converted to yield loss (w\%) from pulp

water held in pores between fibril aggregates and fibril lamellae structures.

Fibre morphology was evaluated by electron and light microscopy. For light microscopy, the pulps were stained with Congo red and the stained samples were examined using Olympus BX61 microscope equipped with a ColorView12 camera in bright field mode. Analysis Pro 3.1 program (Soft Imaging System 


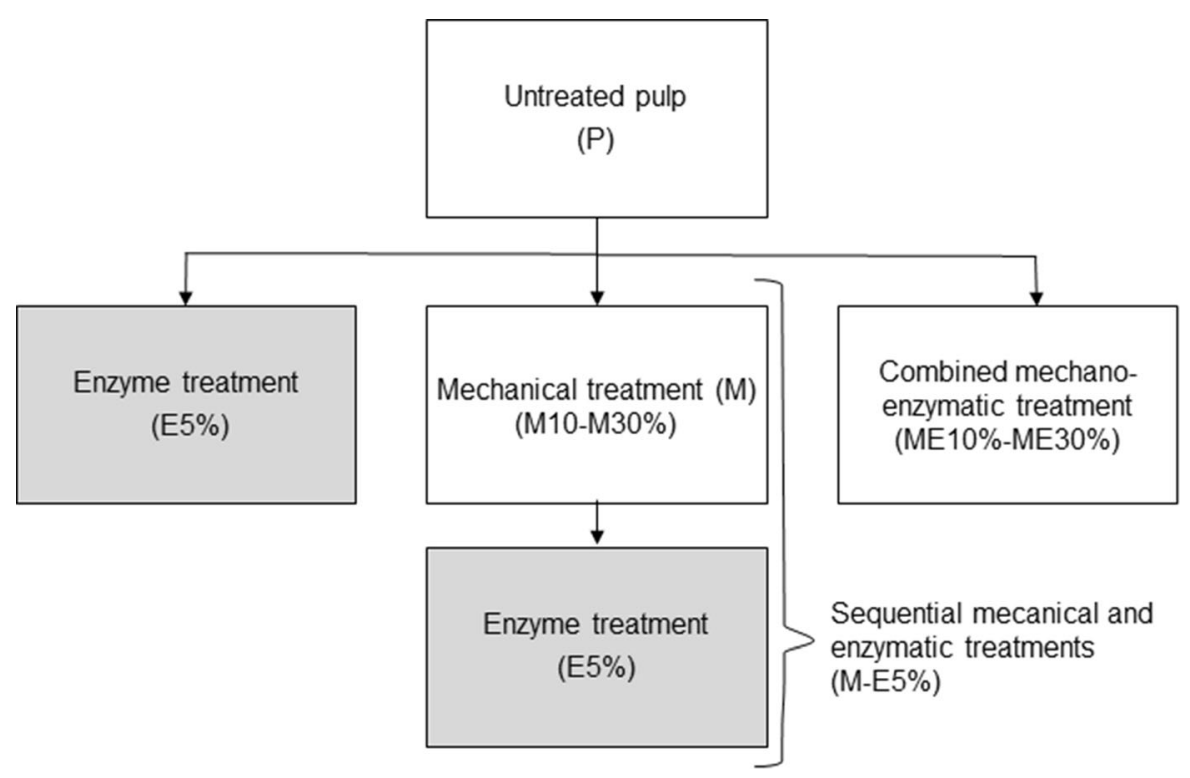

Fig. 2 The experimental setting and nomenclature of the samples. The dry matter content during mechanical (M), enzymatic (E), sequential mechanical and enzymatic (M-E) or combined mechano-enzymatic (ME) treatment is indicated as

$\mathrm{GmbH}$ ) was used for image processing. For scanning electron microscopy (SEM) and surface area analysis, dry fibres with intact pore structure were prepared with critical point drying (CPD). The aqueous pulp samples were first solvent exchanged with $>99.5 \%$ acetone by dialysis over $45 \mathrm{~h}$ and then with liquid carbon dioxide in a critical point drier (Leica EM CPD300) for $1 \mathrm{~h}$. The $\mathrm{CO}_{2}$ was removed during half an hour where the liquid was brought to supercritical state by heating the CPD chamber under pressure $\left(35^{\circ} \mathrm{C}, 75\right.$ bar) before slowly venting it until only $\mathrm{CO}_{2}$ gas at atmospheric pressure remained (Lovikka et al. 2016). Samples were gently placed on a carbon tape for the SEM analysis. The samples were sputtered for 30-90 s with a measured $20 \mathrm{~mA}$ current, which grows a 3-9 nm layer of gold. Images were taken with a secondary electron detector on Sigma VP (Zeiss) SEM with an acceleration voltage of $1.2-1.5 \mathrm{keV}$.

Specific surface area (SSA) was measured by nitrogen sorption apparatus Tristar II (Micromeritics) and the data was collected using software Tristar 3020 (Micromeritics). About $50 \mathrm{mg}$ of critical point dried pulp was placed in sample holder tubes and immediately attached to the instrument. The samples were degassed under vacuum for $1 \mathrm{~h}$ before zeroing the transducers. The isotherms were collected at $77 \mathrm{~K}$ by weight percentages. For example, mechanical treatment at $10 \%$ followed by enzyme treatment at $5 \%$ is marked in the text: M10\%-E5\%. Treatments at low (5\%) and high (10-30\%) consistency are in grey and white boxes, respectively

increasing relative pressure of $\mathrm{N}_{2}$ from 0 to 0.99 and back while recording roughly 150 equilibrium data points (Lovikka et al. 2016). The isotherms were analyzed for surface area using Brunauer-EmmettTeller (BET) equation (Brunauer et al. 1938) at relative pressures between 5 and $35 \%$ where the data points were observed to arrange linearly after applying the BET equation. Molecular cross sectional size of $0.162 \mathrm{~nm}^{2}$ was assumed for $\mathrm{N}_{2}$. The pore size distribution (PSD) for the samples was determined by applying the Barrett, Joyner, and Halenda (BJH) model (Barrett et al. 1951; Kimura et al. 2016) to the adsorption isotherm.

\section{Results and discussion}

Pulp reactivity, linked to fibre structure, can be improved using mechanical and enzymatic pretreatments. A previous study (Grönqvist et al. 2015) demonstrates that combined mechanical and enzymatic treatments with endoglucanase at high consistency result in higher pulp reactivity than separate or sequential treatments. Here, a systematic study was done to find conditions that would optimally promote enzyme action at high consistency and result in a more 


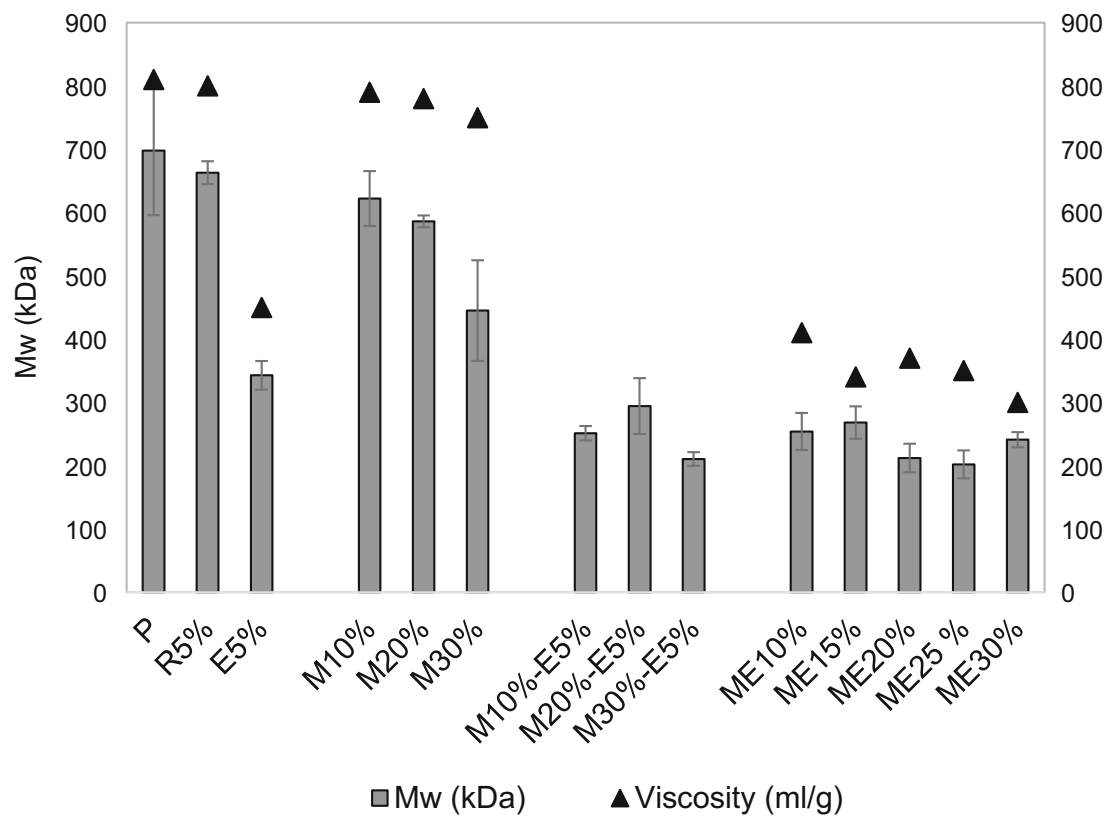

Fig. 3 Weight average molecular weights (Mw) and viscosities of mechanically and enzymatically treated pulps. Untreated pulp (P), pulp treated at low consistency without enzyme (R5\%), pulp treated at low consistency with enzyme (E5\%), pulp treated mechanically at different consistencies (M10\%, M20\%, M30\%), sequential mechanic and enzymatic treatments of pulp

porous and reactive pulp. The experimental setting of pulp treatments is shown in Fig. 2 and the results are summarised in Table 1.

\section{Mechanical treatments without enzyme}

The effect of mechanical treatment (M) on fibre properties was studied after mixing softwood kraft pulp in a farinograph mixer at three consistencies $10 \%, 20 \%$ and $30 \%(\mathrm{w} / \mathrm{w})$. Based on visual appearance from light microscopy images, detectable fibrillation or loosening of the fibre structure was not seen (Fig. 5, panels a-c). Mixing at high consistency was, however, found to decrease the weight average molecular weight $\left(\mathrm{M}_{\mathrm{w}}\right)$ and pulp viscosity (Fig. 3, Table 1). The higher the dry matter during mixing the more pronounce was the effect on the $\mathrm{Mw}$ and viscosity of the pulp. At the highest consistency (M30\%) weight average molecular weight (Mw) was found to decrease from 700 to $490 \mathrm{kDa}$ (Fig. 3, Table 1). The mechanical treatments (M10\%, M20\% and $\mathrm{M} 30 \%)$ were found to increase the mesopore $(3.2 \mathrm{~nm}<\mathrm{D}<54 \mathrm{~nm})$ volumes, while the effect on
(M10\%-E5\%-M30\%-E5\%) and combined mechano-enzymatic treatments of pulp at different consistencies (ME10\%ME30\%). For all analyses at least two replicate samples were dissolved and analysed. For the Mw data, standard deviation is shown in the error bars and for the viscosity data standard deviation of the replicates was within $\pm 10 \mathrm{ml} / \mathrm{g}$

micropores $(<3.2 \mathrm{~nm})$ was minor. The mesopore volume of untreated pulp was $0.35 \mathrm{ml} / \mathrm{g}$ whereas in the mechanically treated pulps the values ranged from 0.43 to $0.48 \mathrm{ml} / \mathrm{g}$ (Fig. 4, Table 1). This indicates that the mechanical action was capable of loosening the bonds between fibril bundles (location of mesopores) rather than swelling the individual fibril aggregates (location of micropores). The same effect has been observed also in previous studies employing different types of pulps and different methods for measuring pore volumes (Stone et al. 1968; Grönqvist et al. 2014). The water retention value (WRV) was also analysed, as the test provides an indication of fibres' ability to uptake water and swell. The mechanical treatments (M10-M30\%) resulted in slightly higher WRV $(1.27-1.30 \mathrm{~g} / \mathrm{g})$ compared to the untreated pulp $(1.14 \mathrm{~g} / \mathrm{g})$ (Fig. 4, Table 1). Interestingly, the WRV remained at the same level despite the consistency in the mechanical treatment. In general, a sole mechanical treatment caused some polymer degradation in the pulp fibres but it had only a minor effect on pulp porosity and morphology. 


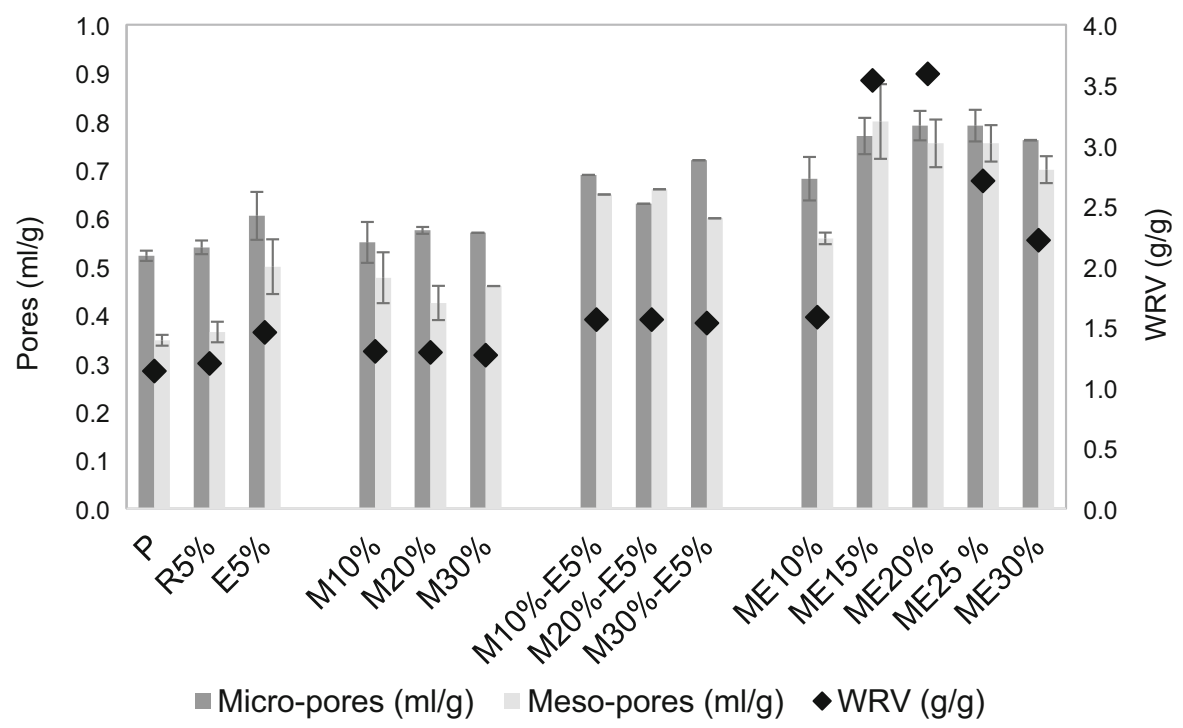

Fig. 4 Micropore volumes, mesopore volumes and water retention values (WRV) of mechanically (M) and enzymatically (E) treated pulps. Untreated pulp (P), pulp treated at low consistency without enzyme (R5\%), pulp treated at low consistency with enzyme (E5\%), pulp treated mechanically at different consistencies (M10\%, M20\%, M30\%), sequential mechanic and enzymatic treatments of pulp (M10\%-E5\%-

\section{Enzymatic treatment at low consistency}

The enzymatic treatment (E) with Fibercare R, an endoglucanase-rich enzyme product, was carried out at low consistency ( $5 \%$ ) for $2 \mathrm{~h}$ using a free fall type of mixing. This experiment was done to demonstrate the effect of the enzyme solely without major mechanical action. The reference treatment (R5\%), done without enzyme, clearly shows that the free fall mixing at low consistency causes only negligible changes in fibre properties ( $\mathrm{Mw}$ and porosity) when compared to the untreated pulp (P) (Table 1). The enzyme treatment at low consistency (E5\%) was found to be more efficient in reducing $\mathrm{Mw}$ and viscosity of the pulp compared to any of the studied mechanical treatments (M10\%, M20\% and M30\%) (Fig. 3, Table 1). The viscosity after enzyme treatment (E5\%) was $450 \mathrm{ml} / \mathrm{g}$ whereas the mechanical treatment at the highest consistency (M30\%) resulted in viscosity of $750 \mathrm{ml} / \mathrm{g}$. Furthermore, the micropore and mesopore volumes as well as the water retention value were higher for the enzyme treated sample (E5\%) than for the mechanically treated samples (M10\%, M20\%, M30\%) (Fig. 4, Table 1). Interestingly, the enzyme treatment alone at low consistency was capable to increase the
M30\%-E5\%) and combined mechano-enzymatic treatments of pulp at different consistencies (ME10\%-ME30\%). All analyses were done in duplicates, except for samples M10\%-E5\%, M20\%-E5\%, M30\%-E5\% and M30\% where only one value was measured. Standard deviation of the WRV results was below $\pm 10 \%$ of the average

micropore volume slightly, which was not possible with the mechanical treatments. The treatment at low consistency (E5\%) was found to dissolve pulp carbohydrates and result in a weight loss of $1.3 \mathrm{w} \%$ from the total mass of fibres which is typical to endoglucanase enzyme treatments. No yield loss was detected for the mechanically treated samples (M10\%, M20\%, M30\%) (Table 1). The used endoglucanase-rich enzyme product (Fibercare $\mathrm{R}$ ) is known to selectively degrade the cellulose in pulp, leaving hemicelluloses intact (Willberg-Keyriläinen et al. 2019). This characteristic for the endoglucanase suggests that the enzyme in the commercial product originates from an endoglucanase family that strictly attacks cellulose (Vlasenko et al. 2010).

Sequential mechanical and enzymatic treatments

In the sequential mechanical and enzymatic treatments the two-hour mechanical pretreatment (M) at high consistency $(10 \%, 20 \%$ or $30 \%)$ was followed by an enzymatic treatment (E) at low (5\%) consistency for $2 \mathrm{~h}$ (Fig. 2). The mechanical pretreatment had a notable effect in boosting the subsequent enzymatic treatment when compared to the sole enzyme 


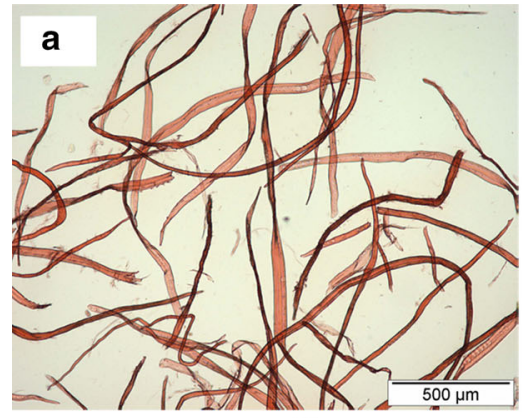

M10\%

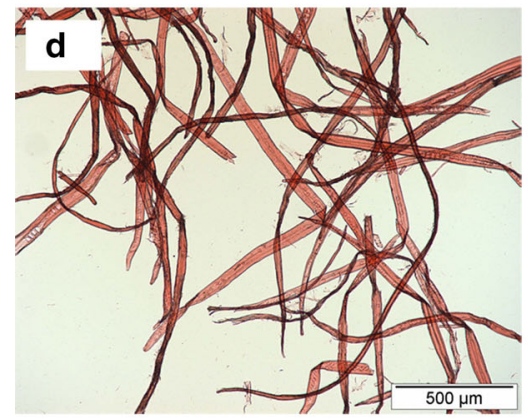

M10\%-E5\%

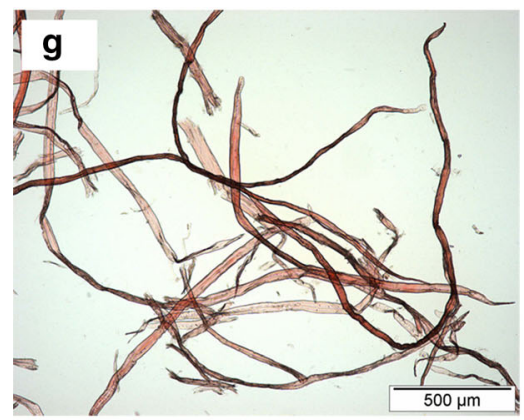

ME10\%

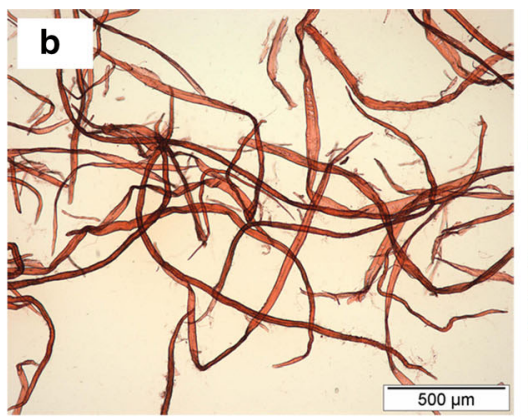

M20\%

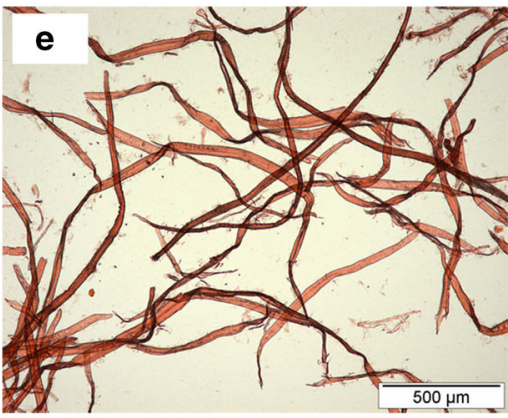

M20-E5\%

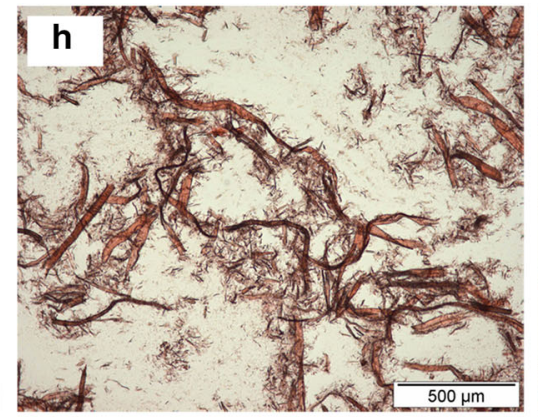

ME20\%

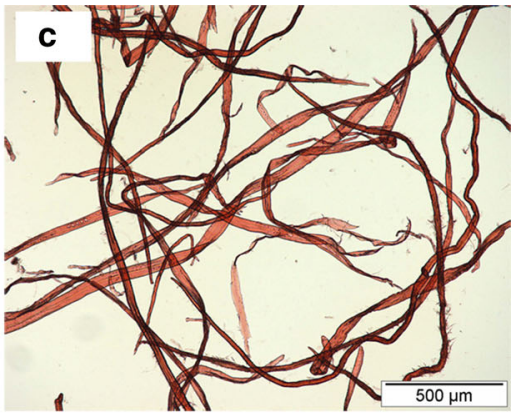

$\mathrm{M} 30 \%$

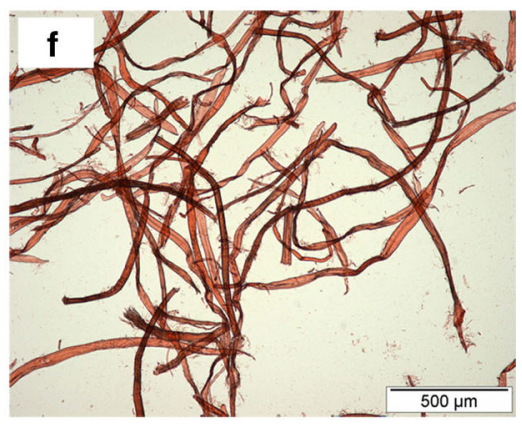

$\mathrm{M} 30 \%-\mathrm{M} 5 \%$

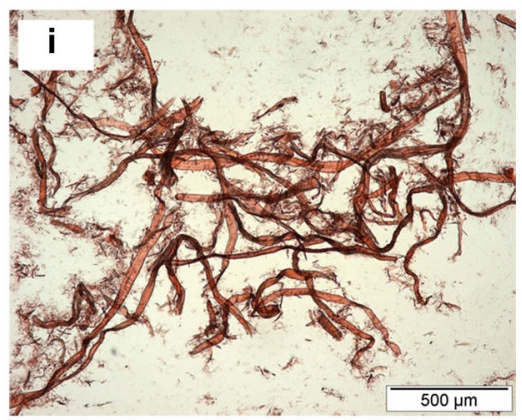

ME30\%
Fig. 5 Light microscopy images of stained softwood kraft fibres after mechanical treatment $(\mathrm{M})$, sequential mechanical and enzymatic treatment (M-E) and combined mechano-

treatment (E5\%), but interestingly the consistency in the mechanical treatment did not have a notable effect on the efficacy of the following enzymatic treatment: the pore volumes, WRVs, and polymer sizes were at the same level in all sequentially treated samples. In a previous study by Grönqvist et al. (2014), increasing time of the mechanical treatment was found to enhance the subsequent enzymatic step. The weight average molecular weights $(\mathrm{Mw})$ of sequentially treated samples were below $300 \mathrm{kDa}$ whereas the enzyme treated sample (E5\%) had a Mw of $340 \mathrm{kDa}$ enzymatic (ME) treatment. The dry matter content during each treatment is indicated as weight percentage

(Fig. 3, Table 1). The water retention values (WRV) of the sequentially treated samples were also slightly higher (ca. $1.55 \mathrm{~g} / \mathrm{g}$ ) compared to the enzyme treated sample (ca. 1.45 g/g) (E5\%) (Fig. 4, Table 1). Fibre porosity (both micropores and mesopores) was clearly increased by sequential treatments compared to the sole enzymatic treatment (E5\%) (Fig. 4, Table 1), indicating that the mechanical pretreatment had, to some extent, opened up the fibre for the following enzymatic treatment. As noted earlier (Grönqvist et al. 2014), enzyme accessibility to the fibre wall is limiting 


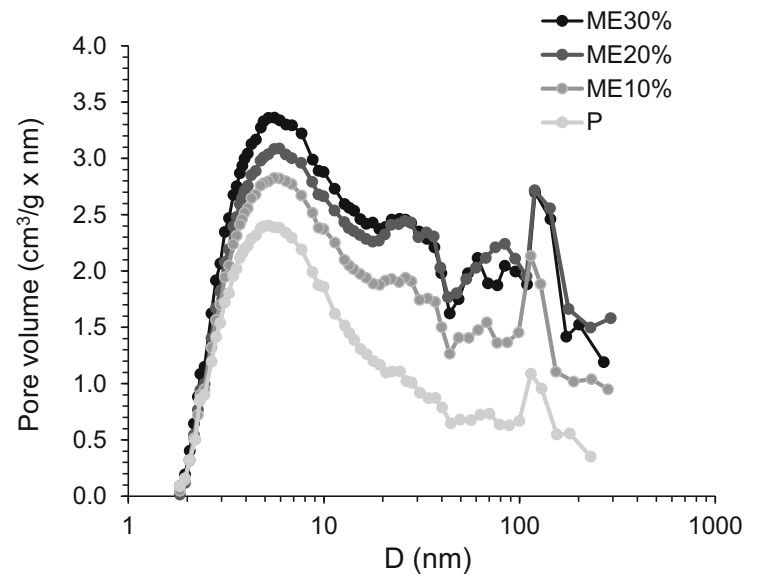

Fig. 6 Pore size distributions (PSD) of mechano-enzymatically (ME) treated pulps treated at different consistencies (10-30\%). The mechano-enzymatically treated pulps and untreated pulp (P) were dried using critical point drying to avoid collapse of the porous structure. Nitrogen gas sorption isotherms and data fitting to a BHJ model were used for determining the distribution

the enzymatic fibre modification approaches. Despite the changes in porosity and $\mathrm{Mw}$, the fibres in sequentially treated samples appeared rather unmodified in the light microscopy images (Fig. 5, panels df).

\section{Combined mechano-enzymatic treatments}

In the combined mechano-enzymatic (ME) treatments the enzymes were present during the 2-h high consistency mixing in a farinograph. The visual appearance of the pulps after mechno-enzymatic treatments (Fig. 5, panels g-i) were radically different compared to the fibres treated with mechanical $(\mathrm{M})$ or sequential mechanical and enzymatic treatments (M-E) (Fig. 5, panels d-f). In particular, mechano-enzymatic treatment at 20\% (ME20\%) and 30\% (ME30\%) consistency (Fig. 5, panels $\mathrm{h}-\mathrm{i}$ ) resulted in fibres that were highly fibrillated from the outer surfaces and the fibres were fragmented. Clearly, high enough consistency $(>10 \%)$ is required for the effect, since mechanoenzymatic treatment at $10 \%$ (ME10\%) did not result in a similar effect (Fig. 5, panel g). Apparently, the mechanical shear between fibres only above $10 \%$ consistency is intensive enough to start fibrillation of the outernmost fibre layers.

The water retention values (WRV) showed a highly interesting trend among the combined mechanoenzymatically treated samples (Fig. 4). At the lowest pulp consistency (ME10\%), the WRV value was at the same level with the sequentially treated samples (ca. $1.55 \mathrm{~g} / \mathrm{g}$ ) but a steep increase in WRV to $3.6 \mathrm{~g} / \mathrm{g}$ was observed when the combined treatment was done at 20\% pulp consistency (ME20\%). Interestingly, higher treatment consistencies (ME25\% and ME30\%) resulted in lower WRV values compared to the treatment carried out at $20 \%$. A similar trend was observed also in mesopore and micropore volume development (Fig. 4). The highest meso- and micropore volumes among all studied samples were measured from the samples ME15\% and ME20\%. The steep increase in WRV and pore volumes is likely due to the increasing amount of fine fibre fragments that are formed during mechano-enzymatic treatment especially at 20\% (ME20\%) (Fig. 5, panel h) but were less abundant if the treatment was carried out at lowed dry matter content 10\% (ME10\%) (Fig. 5, panel g). Previous studies have shown that if a pulp sample is mechanically refined and then fractionated according to particle size the highest WRV and pore volumes are measured from the smallest particles (Stone et al. 1968). A visual inspection of the light microscopy images indicates that the amount of small particles is the highest in the ME20\% sample which would also explain the high WRV and pore volumes. The clear increase in mesopore volumes in mechano-enzymatically treated samples was also supported by pore size distribution determined from dried samples with the nitrogen gas sorption technique (Fig. 6).

In the mechano-enzymatically treated samples (ME10-30\%), there was an increasing trend in released sugars and decreasing trend in pulp viscosity and $\mathrm{Mw}$ with growing consistency, showing that in the combined treatments the enzyme was able to effectively hydrolyse the cellulose polymers in the pulp. The viscosity and Mw values were, however, not fully consistent within the ME10-30\% sample series: the viscosity values show a clear decreasing trend whereas the $\mathrm{Mw}$ values show some fluctuation (Fig. 5). Fluctuation of the Mw results can most probably be explained with the known challenges to completely dissolve softwood kraft pulps prior to size exclusion chromatography (Berthold et al., 2001). At the highest consistency (ME30\%), there were some indications that the enzyme was no longer working efficiently: the release of sugars was $0.1 \%$ lower and the $\mathrm{Mw}$ was $40 \mathrm{kDa}$ higher than after the ME25\% treatment. The results supports the previous findings (Modenbach and 

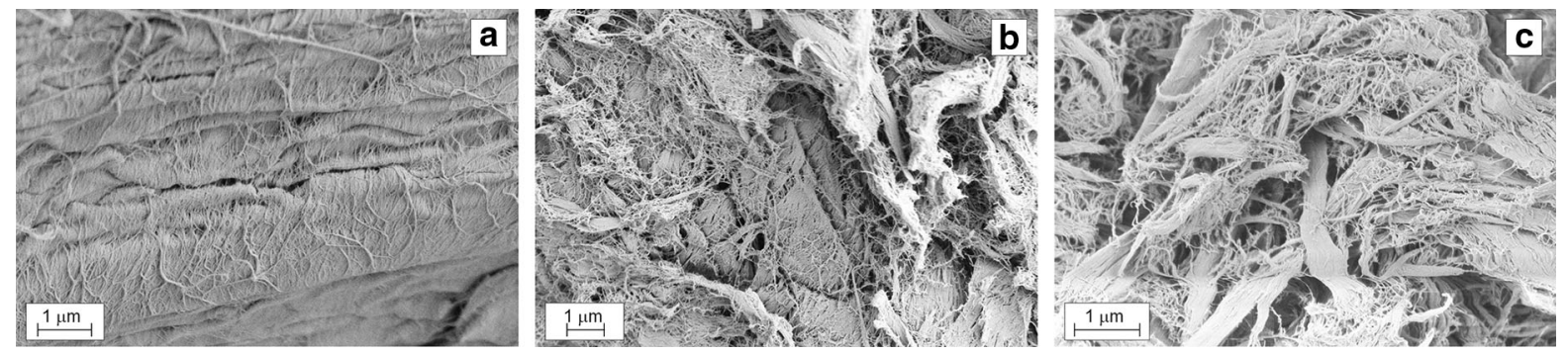

Fig. 7 SEM micrographs of a unmodified pulp fibres (P), b fibres after combined mechano-enzymatic treatment at 20\% (ME20\%) and c fibres after combined mechano-enzymatic treatment at 30\% (ME30\%)

Nokes 2013) suggesting that at high consistency the reaction is limited by amount of free water for hydrolysis and mass transport. It seems that, in the studied conditions, the most optimal consistency for mechano-enzymatic fibre treatment, where the most radical effect on fibre morphology and porosity was achieved, was around 20\% (w/w). According to a previous study, high porosity of pulp correlates with good fibre dissolution in $\mathrm{NaOH} / \mathrm{ZnO}$ (Grönqvist et al. 2014).

The pore size distribution (PSD) in the mesoporeand small macropore size range $(3-300 \mathrm{~nm})$ was studied in more detail with the mechano-enzymatically treated samples (ME10\%, ME20\% and ME30\%) using nitrogen gas adsorption isotherms and data fitting to a BJH model (Fig. 6). In general, mesopore volumes were found to increase with increasing treatment consistency up to $20 \%$ consistency. This observation is in accordance with the solute exclusion data on mesopore volumes (Fig. 4). Interestingly, the increase in pore volumes was not constant across the whole measurement range. Volume in the smallest pores of the distribution $(3 \mathrm{~nm}>\mathrm{D}>7 \mathrm{~nm})$ was found to increase constantly with increasing treatment consistency. However, volume in pores with diameter above $10 \mathrm{~nm}$ was found to reach maximum after treatment at $20 \%$ consistency and the volume was similar in the ME20\% and ME30\% samples. The volume in mesopores (diameter 3.2-54 nm) measured by solute exclusion technique was found to slightly decrease between treatments ME20\% and ME30\% (from $0.75 \mathrm{ml} / \mathrm{g}$ to $0.70 \mathrm{ml} / \mathrm{g}$ ). Decrease of the mesopore volumes could, however, not be seen with the nitrogen sorption technique (Fig. 6). Drying of the pulp samples, which is done prior to measurement with the nitrogen sorption technique, is known to alter the pore networks compared to wet samples.
Therefore, direct correlation of porosity data in Figs. 4 and 6 cannot be expected.

Interestingly, a clear increase in pore volume at the range $20-30 \mathrm{~nm}$ emerged after the mechano-enzymatic treatments and the effect was most pronounced after mechano-enzymatic treatments at 20 and $30 \%$ consistencies. Increase in pore volumes at the 20-30 $\mathrm{nm}$ range may be due to increasing porosity between the cellulose fibril aggregates. Pore opening was also evident at 100-200 $\mathrm{nm}$ range, which suggests that the mechano-enzymatic treatments delaminate the cell walls. The delaminating effect was supported by the scanning electron micrograph (SEM) images that showed considerable defibrillation and fracture of the cell walls after mechano-enzymatic treatments (Fig. 7). Other visual evidences of fibre disintegration after mechano-enzymatic treatments involved emerging of loose fibril ends to otherwise neat fibre surfaces and long cracks or ruptures of the outermost layers that revealed the layers beneath. In general, the SEM images showed that disruption of the fibre walls occurred unevenly: some areas of the fibres appeared highly disrupted and fibrillated whereas certain areas appeared more intact.

The endoglucanase enzymes and mechanical shear forces together seem to cause a synergistic effect that efficiently unbundles the coherent structure of the kraft fibres at low enzyme dosages $(0.25 \mathrm{mg}$ enzyme protein/g dry pulp) and in relatively short time ( $2 \mathrm{~h})$. Endoglucanase accessibility to kraft fibres is limited by enzyme size. The smallest endoglucanases that have been applied in fibre modification are ca. $3 \times 5 \mathrm{~nm}$ in diameter (Rahikainen et al. 2019). A recent study by Imai et al. (2019) showed with a fluorescent labelled cellulase mix that complete enzyme penetration to a never dried softwood kraft fibre takes 4-25 h (Imai et al. 2019). Hornification of 
the fibres was found to reduce the accessibility even further. Therefore, mechanical shear is necessary to disrupt the fibre structure and speed-up enzyme penetration to the fibre wall.

It was evident from the sequentially treated (M-E) samples that mechanical forces disrupted the fibre surface and generated more pore volume in the mesopore-range. These pores are likely accessible for the endoglucanase enzymes and thus the enzyme action was enhanced in the sequentially treated samples compared to the reference treatment (E5\%). However, in the mechano-enzymatically treated samples the effect was clearly synergistic. It can be hypothesized that in the combined mechano-enzymatic treatments the mechanical shear first allows enzyme penetration deeper to the fibre wall where the hydrolytic action likely weakens the coherence of the fibre wall. The weakened fibres are likely more easily disrupted by further mechanical fibre-fibre friction that also further promotes enzyme action.

\section{Conclusions}

Combined mechano-enzymatic treatment of bleached softwood kraft pulp at high consistency with low endoglucanase dosage effectively disrupted fibre structure compared to low consistency enzyme treatment alone or sequential mechanical and enzymatic treatments. The disruptive effect of the combined mechano-enzymatic treatment was dependent on the dry matter content of the treatment. Fibre properties that indicate improved cellulose accessibility and reactivity, fibre porosity and ability to retain water (WRV), were most affected when the mechanoenzymatic pulp treatment was carried out at 15-25 w\% consistency. The mechano-enzymatic treatment at high consistency was found to result in extensive surface fibrillation that is likely a major cause for the increased WRV and porosity values. The mechanoenzymatic treatments at high consistency offer an industrially relevant alternative for improving fibre reactivity with relatively low enzyme load and short processing time.

Acknowledgments Open access funding provided by Technical Research Centre of Finland (VTT). This work was funded by the Academy of Finland Grants Nos. 277791 and 279255 for the project "Development of porosity at high solids loading in the early stages of fibre treatment by cellulose-active enzymes". In addition, we are grateful for the support by the FinnCERES Materials Bioeconomy Ecosystem (Academy of Finland). Analytical expertise of Atte Mikkelson and technical assistance of Mariitta Svanberg and Leena Nolvi is gratefully acknowledged.

Open Access This article is licensed under a Creative Commons Attribution 4.0 International License, which permits use, sharing, adaptation, distribution and reproduction in any medium or format, as long as you give appropriate credit to the original author(s) and the source, provide a link to the Creative Commons licence, and indicate if changes were made. The images or other third party material in this article are included in the article's Creative Commons licence, unless indicated otherwise in a credit line to the material. If material is not included in the article's Creative Commons licence and your intended use is not permitted by statutory regulation or exceeds the permitted use, you will need to obtain permission directly from the copyright holder. To view a copy of this licence, visit http://creativecommons.org/licenses/by/4.0/.

\section{References}

Bailey MJ, Biely P, Poutanen K (1992) Interlaboratory testing of methods for assay of xylanase activity. J Biotechnol 23:257-270. https://doi.org/10.1016/01681656(92)90074-J

Barrett EP, Joyner LG, Halenda PP (1951) The determination of pore volume and area distributions in porous substances. I. Computations from nitrogen isotherms. J Am Chem Soc 73:373-380. https://doi.org/10.1021/ja01145a126

Bernfeld P (1955) Amylases, $\alpha$ and $\beta$. In: Colowick SP, Nok AJ (eds) Methods in enzymology. Academic Press, NY, pp 149-158

Berthold F, Gustafsson K, Sjöholm E, Lindström M (2001) An improved method for the determination of softwood kraft pulp molecular mass distributions. In: 11th International symposium on wood and pulping chemistry (June 11-14, Nice, France). pp 363-366

Brunauer S, Emmett PH, Teller E (1938) Adsorption of gases in multimolecular layers. J Am Chem Soc 60:309-319. https://doi.org/10.1021/ja01269a023

Buchert J, Siika-aho M, Bailey M et al (1993) Quantitative determination of wood-derived soluble oligosaccharides by HPLC. Biotechnol Tech 7:785-790. https://doi.org/10. 1007/BF00153745

Gehmayr V, Schild G, Sixta H (2011) A precise study on the feasibility of enzyme treatments of a kraft pulp for viscose application. Cellulose 18:479-491. https://doi.org/10. 1007/s10570-010-9483-x

Ghose TK (1987) Measurement of cellulase activities. Pure Appl Chem 59:257-268. https://doi.org/10.1351/ pac198759020257

Grönqvist S, Hakala TK, Kamppuri T et al (2014) Fibre porosity development of dissolving pulp during mechanical and enzymatic processing. Cellulose 21:3667-3676. https:// doi.org/10.1007/s10570-014-0352-x 
Grönqvist S, Kamppuri T, Maloney T et al (2015) Enhanced pretreatment of cellulose pulp prior to dissolution into $\mathrm{NaOH} /$ ZnO. Cellulose 22:3981-3990. https://doi.org/10.1007/ s10570-015-0742-8

Imai M, Furujo A, Sugiyama J (2019) Direct observation of cellulase penetration in oven-dried pulp by confocal laser scanning microscopy. Cellulose 26:7653-7662. https://doi. org/10.1007/s10570-019-02676-7

Kimura M, Qi ZD, Isogai A (2016) Analysis of mesopore structures in wood cell walls and pulp fibers by nitrogen adsorption method. Nord Pulp Pap Res J 31:198-204. https://doi.org/10.3183/npprj-2016-31-02-p198-204

Köpcke V, Ibarra D, Ek M (2008) Increasing accessibility and reactivity of paper grade pulp by enzymatic treatment for use as dissolving pulp. Nord Pulp Pap Res J 23:363-368. https://doi.org/10.3183/NPPRJ-2008-23-04-p363-368

Li J, Zhang S, Li H et al (2018) A new approach to improve dissolving pulp properties: spraying cellulase on rewetted pulp at a high fiber consistency. Cellulose 25:6989-7002. https://doi.org/10.1007/s10570-018-2063-1

Lovikka VA, Khanjani P, Väisänen S et al (2016) Porosity of wood pulp fibers in the wet and highly open dry state. Microporous Mesoporous Mater 234:326-335. https://doi. org/10.1016/j.micromeso.2016.07.032

Lovikka VA, Rautkari L, Maloney TC (2018) Changes in the hygroscopic behavior of cellulose due to variations in relative humidity. Cellulose 25:87-104. https://doi.org/10. 1007/s10570-017-1570-9

Lowry OH, Rosebrough NJ, Farr AL, Randall RJ (1951) Protein measurement with the Folin phenol reagent. J Biol Chem 193:265-275

Manninen MA, Nieminen KL, Maloney TC (2013) The swelling and pore structure of microfibrillated cellulose. In: L'Anson SJ (ed) Advances in pulp and paper science research, Cambridge 2013, Transactions of the 15th fundamental research symposium vol 2. The Pulp and Paper Fundamental Research Society, Manchester, pp 765-785

Miao Q, Tian C, Chen L et al (2015) Combined mechanical and enzymatic treatments for improving the Fock reactivity of hardwood kraft-based dissolving pulp. Cellulose 22:803-809. https://doi.org/10.1007/s10570-014-0495-9

Modenbach AA, Nokes SE (2013) Enzymatic hydrolysis of biomass at high-solids loadings: a review. Biomass Bioenergy 56:526-544. https://doi.org/10.1016/ j.biombioe.2013.05.031

Pönni R, Kontturi E, Vuorinen T (2013) Accessibility of cellulose: Structural changes and their reversibility in aqueous media. Carbohydr Polym 93:424-429. https://doi.org/10. 1016/j.carbpol.2012.12.025

Rahikainen J, Ceccherini S, Molinier M et al (2019) Effect of cellulase family and structure on modification of wood fibres at high consistency. Cellulose 26:5085-5103. https:// doi.org/10.1007/s10570-019-02424-x
Rahkamo L, Siika-Aho M, Vehviläinen M et al (1996) Modification of hardwood dissolving pulp with purified Trichoderma reesei cellulases. Cellulose 3:153-163

Seo YB, Shin YC, Jeon Y (2000) Enzymatic and mechanical treatment of chemical pulp. TAPPI J 83:11-64

Sluiter A, Hames B, Ruiz R, et al (2008) Determination of structural carbohydrates and lignin in biomass, laboratory analytical procedure (LAP)

Stone JE, Scallan AM (1965) Effect of component removal upon the porous structure of the cell wall of wood. J Polym Sci Part C 11:13-25. https://doi.org/10.1002/polc.5070110104

Stone JE, Scallan AM (1968) A structural model for the cell wall of water-swollen wood pulp fibres based on their accessibility to macromolecules. Cellul Chem Technol 2:343-358

Stone JE, Scallan AM (1967) The effect of component removal upon the porous structure of the cell wall of wood. II. Swelling in water and the fiber saturation point. TAPPI 50:496-501

Stone JE, Scallan AM, Abrahamson B (1968) Influence of beating on cell wall swelling and internal fibrillation. Sven papperstidning 687-694

Sumner JB, Noback CV (1924) The estimation of sugar in diabetic urine, using dinitrosalicylic acid. J Biol Chem 62:287-290

Várnai A, Siika-aho M, Viikari L (2013) Carbohydrate-binding modules (CBMs) revisited: reduced amount of water counterbalances the need for CBMs. Biotechnol Biofuels 6:30. https://doi.org/10.1186/1754-6834-6-30

Virtanen T, Penttilä PA, Maloney TC et al (2015) Impact of mechanical and enzymatic pretreatments on softwood pulp fiber wall structure studied with NMR spectroscopy and X-ray scattering. Cellulose 22:1565-1576. https://doi.org/ 10.1007/s10570-015-0619-x

Vlasenko E, Schülein M, Cherry J, Xu F (2010) Substrate specificity of family $5,6,7,9,12$, and 45 endoglucanases. Bioresour Technol 101:2405-2411. https://doi.org/10. 1016/j.biortech.2009.11.057

Wang Q, Liu S, Yang G et al (2015) High consistency cellulase treatment of hardwood prehydrolysis kraft based dissolving pulp. Bioresour Technol 189:413-416. https://doi.org/ 10.1016/j.biortech.2015.04.069

Wang Q, Fu X, Liu S et al (2020) Understanding the effects of depth refining on upgrading of dissolving pulp during cellulase treatment. Ind Crop Prod 144:112032. https://doi. org/10.1016/j.indcrop.2019.112032

Willberg-Keyriläinen P, Ropponen J, Lahtinen M, Pere J (2019) Improved reactivity and derivatization of cellulose after pre-hydrolysis with commercial enzymes. BioResources 14:561-574. https://doi.org/10.15376/biores.14.1.561-574

Publisher's Note Springer Nature remains neutral with regard to jurisdictional claims in published maps and institutional affiliations. 